\title{
Isolated Central Hypothyroidism in Short Stature
}

\author{
SUSAN R. ROSE \\ Department of Pediatrics, University of Tennessee, Memphis, Tennessee 38103-4901
}

\begin{abstract}
Mild hypothyroidism can be difficult to diagnose, particularly
when it is caused by deficiency of TSH or TSH-releasing hor-
mone (TRH). Such central hypothyroidism occurs most often in
association with growth hormone deficiency (GHD). Isolated
central hypothyroidism has been considered rare. The TSH surge
test is the most sensitive test currently available for confirming
the diagnosis. Results are abnormal in many cases where re-
sponse to TRH is normal. Short children referred between 1986
and 1994 for evaluation ( $n=235$, 74 girls; height 2 or more SD
below mean for age; no history of radiation therapy) were
selected for study. TSH samples were obtained hourly for study
of TSH surge (1400-1800 h and $2200-0400$ h). Growth hor-
mone (GH) samples were obtained every 20 min ( $2000-0800$ h).
GH stimulation tests included arginine, insulin, and L-dopa.
Thirty-nine children were found to have GHD (peak GH $\leq 7$
$\mu \mathrm{g} / \mathrm{L}$ ) and 15 had mild primary hypothyroidism (TSH $5-15$
mU/L). Of the remaining 181 children with apparent idiopathic
short stature (ISS), 30 had a blunted TSH surge. All 30 had free
thyroxine (FT ${ }_{4}$ ) in the lowest third of the normal range, consis-
\end{abstract}
ABSTRACT

The etiology of short stature in slowly growing children who are not $\mathrm{GH}$ deficient continues to be diagnostically challenging (1-4). Some clinicians have proposed that such children must have insufficient $\mathrm{GH}$ secretion (5-7) despite normal results on standard tests of stimulated or spontaneous GH (8-10) (Rose $\mathrm{SR}$, unpublished data). Others have sought subtle hormonal or medical abnormalities as the cause of the short stature.

Mild hypothyroidism can cause slowed growth. In mild primary hypothyroidism, slightly elevated TSH concentrations serve to alert the clinician to the disorder. However, in mild TSH-D, caused by loss of normal hypothalamic-pituitary regulation of the circadian pattern of TSH secretion, morning TSH concentrations are most often normal. As a result, the diagnosis can be very difficult to confirm even when suspected. Most commonly, TSH-D is suspected in patients with an already identified hypothalamic-pituitary disorder (11-13). Iodothyronine levels in TSH-D are commonly only slightly below the

Received February 13, 1995; accepted June 14, 1995

Correspondence and reprint requests: Susan R. Rose, M.D., 848 Adams Ave., Fourth Floor, Memphis, TN 38103.

Supported in part by each of the following: National Institute of Child Health and Human Development of the National Institutes of Health, GCRC 5M01-RR00997 University of New Mexico, and GCRC M01-RR00211 University of Tennessee, Memphis. tent with values seen in documented central hypothyroidism. They were $13 \%$ of the total group, $16 \%$ of the ISS children, and $32 \%$ of the ISS children with $\mathrm{FT}_{4}$ in the lowest third of normal. (In comparison, diagnosis of GHD was made in $16 \%$ of the total group.) In conclusion, use of a direct $\mathrm{FT}_{4}$ assay to screen short children for possible subtle hypothyroidism (along with other appropriate testing) identifies a subgroup with a one in three possibility of an easily treated cause-isolated central hypothyroidism. (Pediatr Res 38: 967-973, 1995)

TRH, TSH-releasing hormone

$\mathbf{T}_{4}$, thyroxine

$\mathrm{FT}_{4}$, free $\mathrm{T}_{4}$

TSH-D, central hypothyroidism

GH, growth hormone

GHD, GH deficiency

ISS, idiopathic short stature group normal range, and TSH concentrations are commonly within the normal range. Some patients with iodothyronine levels in the lower part of the normal range and with normal TSH concentrations may also have TSH-D due to dysfunction of TSH secretion. Such values may be interpreted as normal. These patients may remain clinically puzzling and thus are often not treated with thyroid replacement medication. Failure to recognize and treat TSH-D can result in poor growth and less than optimal state of health $(13,14)$.

In normal infants, children, and adults, the circadian pattern of serum TSH concentration is characterized by declining values throughout the morning, nadir values in the afternoon, and an approximate doubling or surge in the evening with peak values in the early morning (15-20). In normal children and adults, nocturnal TSH concentrations typically rise $50-300 \%$ above the nadir value after early evening. In the TSH surge test, the circadian pattern of TSH secretion is sampled as a probe of the intactness of the hypothalamic-pituitary-thyroid axis $(11,16)$. The author has previously shown that in TSH-D the nocturnal TSH surge is blunted or absent, the nocturnal TSH surge is a sensitive (and specific) test for identification of TSH-D, whereas use of a TRH test is less sensitive than the TSH surge in children with multiple hormone deficiencies (11). 
It was hypothesized that some slowly growing children with no other identifiable cause of their short stature might have isolated TSH-D. This report describes the incidence of isolated TSH-D identified using the nocturnal TSH surge in children otherwise diagnosed with ISS.

\section{METHODS}

The study was approved by the Human Research Committee at each of the following institutions: the National Institute of Child Health and Human Development of the National Institutes of Health (National Institutes of Health), the University of New Mexico (UNM), and the University of Tennessee, Memphis (UT). The population from which children were identified for this study included all sequential admissions by the author between 1986 and 1994 for evaluation of height two or more SD below the mean for age. Two-thirds of the children were male ( $n=235$, ages 1-17 y, 74 girls), consistent with frequently found referral patterns in the United States. Causes for exclusion included intercurrent acute or chronic illness, glucocorticoid requirement, depression or other psychiatric diagnosis, rapid growth, history of radiation therapy for oncologic processes, Turner syndrome, and skeletal dysplasias. The subjects were admitted to the National Institutes of Health Clinical Center, the UNM General Clinical Research Center, or the UT General Clinical Research Center.

Procedures. Signed informed consent was obtained from one parent and assent from each child. Morning height was measured by stadiometer. Radiograph of the left hand and wrist was interpreted for bone maturation according to the standards of Greulich and Pyle. A standard pediatric diet was provided, and sleep period was monitored by nursing observation.

An i.v. catheter for blood drawing access was maintained with $0.5-1.0 \mathrm{~mL}$ of heparin $(100 \mathrm{U} / \mathrm{mL})$ after each blood draw. Blood samples were drawn hourly from 1400 until $1800 \mathrm{~h}$ (time of TSH nadir) and from 2200 until $0400 \mathrm{~h}$ (time of TSH peak) for TSH assay (Fig. 1). Simultaneous study of overnight GH concentrations (2000 until $0800 \mathrm{~h}$, every $20 \mathrm{~min}$ of sampling for GH assay) was performed in 162 of the children. Subsequently, standard GH stimulation tests (arginine, insulin, and $\mathrm{L}$-dopa; or arginine and $\mathrm{L}$-dopa) were performed in all children after pretreatment with estradiol in peripubertal children (older than age 8 but not yet stage 3 of puberty) $(8,10)$. TRH test (protirelin $7 \mu \mathrm{g} / \mathrm{kg}$ i.v., maximum dose, $500 \mu \mathrm{g}$ ) was performed in 145 of the children (11).

To evaluate the clinical utility of the TSH surge in predicting growth response to therapy with thyroid hormone, a pilot study was performed. Ten of the ISS children with $\mathrm{FT}_{4}$ in the lowest third of the normal range, 22 of the ISS children with $\mathrm{FT}_{4}$ in the upper two-thirds of the normal range, and 6 of the children with $\mathrm{FT}_{4}$ in the lowest third of the normal range and blunted TSH surge participated in a treatment trial during $18 \mathrm{mo}$, with evaluation of basal growth velocity during the first and third 6-mo intervals. During the second 6-mo interval, patients took levothyroxine (Synthroid) daily in doses that achieved an increase in serum $\mathrm{FT}_{4}$ concentration of $6.0 \pm 1.0 \mathrm{pmol} / \mathrm{L}$ (mean $\pm \mathrm{SD}$ ), resulting in $\mathrm{FT}_{4}$ concentrations during treatment that remained in the normal range. The Synthroid dose required

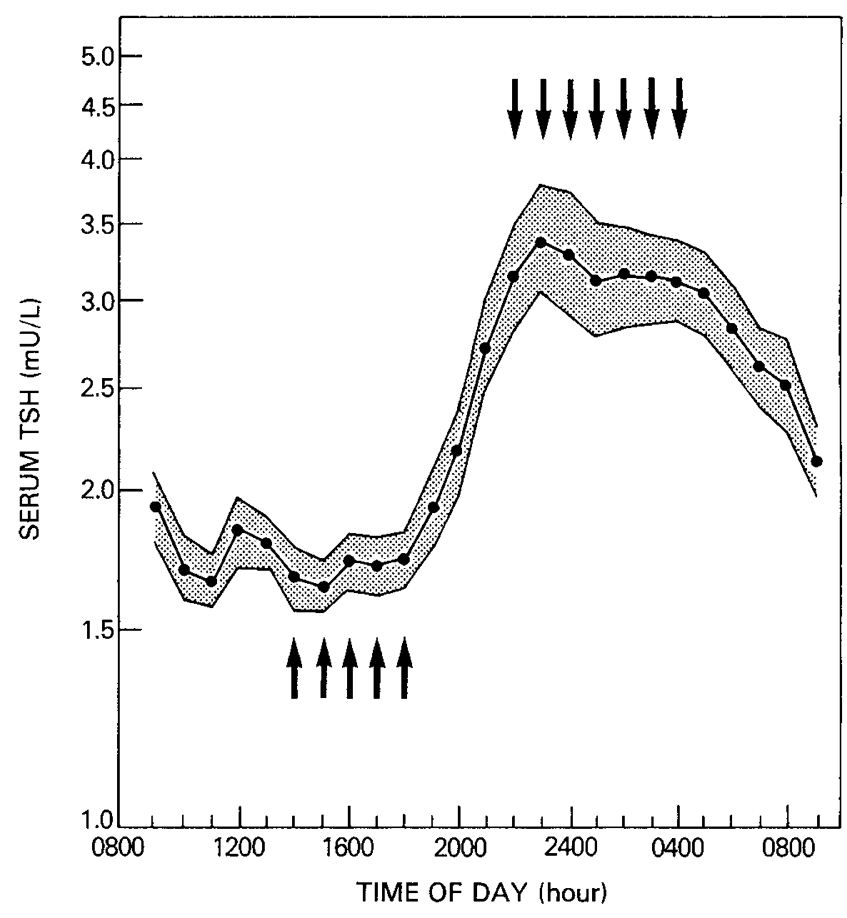

Figure 1. Assessment of the nocturnal TSH surge. The closed circles indicate the mean serum TSH and the shaded region represents \pm 2 SE in 96 normal children. Arrows signify sampling times. The nadir TSH was the mean of the three consecutive lowest TSH values in the afternoon. The peak TSH was the mean of the three consecutive highest TSH values in the night. TSH surge (\%) $=100 \times($ peak - nadir $) /$ nadir. [Adapted from Rose and Nisula (16).]

in these children to achieve treatment concentrations was $2.8 \pm$ $0.4 \mu \mathrm{g} / \mathrm{kg} / \mathrm{d}$. Growth velocity data were used in analysis only from those children who remained prepubertal throughout the 18-mo period.

Assays. The specific methodology available for TSH assay was different at each study location; however, each assay was ultrasensitive and involved antibodies to three sites on the TSH molecule (Table 1). Because each patient's peak TSH value was analyzed relative to his or her own nadir TSH value, minor differences between assays were compensated for in interpre-

Table 1. $\mathrm{FT}_{4}$ and TSH assay available at the study locations: National Institutes of Health (NIH), University of New Mexico (UNM), and University of Tennessee Memphis (UT)

\begin{tabular}{|c|c|c|c|}
\hline Assay & $\begin{array}{l}\text { Normal } \\
\text { range }\end{array}$ & Method & $\begin{array}{l}\text { Cut-off used to } \\
\text { identify lower } \\
\text { third of } \\
\text { normal range }\end{array}$ \\
\hline \multicolumn{4}{|c|}{$\mathrm{FT}_{4}(\mathrm{pmol} / \mathrm{L})^{a}$} \\
\hline $\mathrm{NIH}$ & $13-26$ & Baxter-Travelol & $\leq 17$ \\
\hline UNM & $10-32$ & Ciba-Corning & $\leq 17$ \\
\hline UT & $9-24$ & Abbott & $\leq 14$ \\
\hline \multicolumn{4}{|c|}{$\mathrm{TSH}(\mathrm{mU} / \mathrm{L})^{b}$} \\
\hline $\mathrm{NIH}$ & $0.5-4.6$ & $\begin{array}{l}\text { Ciba-Serono } \\
\text { Maiaclone TSH, IRMA }\end{array}$ & \\
\hline UNM & $0.6-4.6$ & $\begin{array}{l}\text { Nichols Allegro } \\
\text { HS-TSH RIA }\end{array}$ & \\
\hline UT & $0.32-5.0$ & $\begin{array}{l}\text { Abbott IMX US TSH } \\
\text { MEIA }\end{array}$ & \\
\hline
\end{tabular}

\footnotetext{
${ }^{a}$ To convert $\mathrm{FT}_{4}$ to SI units, $\mathrm{ng} / \mathrm{dL} \times 12.87=\mathrm{pmol} / \mathrm{L}$.
}

${ }^{b}$ To convert TSH to SI units, $\mathrm{mcU} / \mathrm{mL} \times 1.0=\mathrm{mU} / \mathrm{L}$. 
tation of results. $\mathrm{FT}_{4}$ assay at each study site involved direct RIA of $\mathrm{FT}_{4}$ rather than calculated or derived values (Table 1).

Serum GH was assayed by polyclonal RIA: National Institutes of Health and UNM samples at Hazleton Washington (Vienna, VA), and UT samples at Endocrine Sciences (Calabasas Hills, CA). Samples for all spontaneous $\mathrm{GH}$ studies were assayed at Hazleton Washington.

Analysis. The short children were divided into four groups (Table 2): ISS included children with entirely normal GH and thyroid studies; the GHD group (peak stimulated GH of $7 \mu \mathrm{g} / \mathrm{L}$ or less); the high TSH group included children with mild primary hypothyroidism (TSH 5-15 mU/L); and the TSH-D group (blunted TSH surge).

Peak GH referred to the highest $\mathrm{GH}$ value observed during any stimulation test. Mean night $\mathrm{GH}$ referred to the mean of all $37 \mathrm{GH}$ values obtained during the overnight $\mathrm{GH}$ study (21).

The nocturnal TSH surge was calculated by subtracting the TSH nadir (three sequential values in the afternoon yielding the lowest mean TSH) from the TSH peak (three sequential values at night yielding the highest mean $\mathrm{TSH}$ ) and dividing the difference by the TSH nadir, expressing the result as percent rise over nadir (Fig. 1). Results were compared with $95 \%$ confidence limits of values observed in 96 normal children previously reported by the author (16). TSH surge results between 50 and $300 \%$ were considered normal.

The TRH test was evaluated according to magnitude of TSH peak (amount of rise above baseline TSH level), time of TSH peak (minutes after TRH was given), and response curve decline (percent of magnitude of TSH peak remaining at 60 min after time of TSH peak). Results were compared with $95 \%$ confidence limits of values observed by the author in 76 normal children (11).

Analysis of variance with the Bonferroni adjustment for multiple comparisons was used to evaluate possible statistical differences among groups. Repeated measures analysis of variance was used in evaluating changes in growth velocity in the treatment trial.

\section{RESULTS}

During the 9-y period of study, the author diagnosed in this population 39 children with GHD (GH peak $\leq 7 \mathrm{ng} / \mathrm{dL}$ ) and 15 children with mild primary hypothyroidism (TSH at $0900 \mathrm{~h}$,
5-15 mU/L) not previously apparent as an outpatient. The remaining 181 children met generally accepted criteria for the diagnosis of ISS.

However, 30 of the 181 children (four girls, 13\%) were found to have a low TSH surge, whereas 151 children (51 girls, $33 \%$ ) had a normal TSH surge (Table 3). All 30 children with a blunted TSH surge had $\mathrm{FT}_{4}$ in the lower third of the normal range. Thus, use of a $\mathrm{FT}_{4}$ cutoff value dividing the lower third from the rest of the normal range (to identify a subgroup of short children in whom the TSH surge should be performed) would have identified $100 \%$ of these children with isolated TSH-D (Fig. 2).

The children with TSH-D were $13 \%$ of the total group of referred short children but were $32 \%$ of the 92 children with apparent ISS who had $\mathrm{FT}_{4}$ in the lowest third of the normal range. By comparison, GHD was concurrently diagnosed in $16 \%$ of the total group of referred short children. Of 39 children diagnosed with GHD, $7(18 \%)$ were identified as also having TSH-D, a commonly associated deficiency. The incidence of children with TSH-D was similar at each of the study locations, suggesting no regional differences in distribution of diagnoses. Bone age was significantly delayed in GHD (2.1 y) and $1.9 \mathrm{y}$ delayed in TSH-D, whereas delay was less in the other groups (1.2 y in high TSH, $1.5 \mathrm{y}$ in ISS) (Table 2).

TSH response to TRH did not differ significantly among groups, with the exception of high TSH in which an exaggerated magnitude of TSH peak response to TRH was seen (Table 3 ). In TSH-D, only 2 of the 22 patients who had the TRH test performed had delayed time of TSH peak and also delayed response curve decline. No patient had a subnormal magnitude of TSH peak (Fig. 3). Thus, TRH testing would have failed to confirm the diagnosis in $91 \%$ of the TSH-D patients.

The peak stimulated $\mathrm{GH}$ and mean night $\mathrm{GH}$ results in GHD were significantly lower than in ISS (both $p<0.01$ ). However, GH results in TSH-D or high TSH were not different from $\mathrm{GH}$ results in ISS (Table 2). Both hypothyroid groups had mean $\mathrm{FT}_{4}$ values which were significantly lower than mean $\mathrm{FT}_{4}$ in the ISS group, but which remained within the low part of the normal range. These observations suggest that mild hypothyroidism of the degree observed in these two groups does not in itself significantly alter the clinician's ability to accurately and simultaneously assess GH status (Fig. 4).

Table 2. Clinical characteristics of the 235 children with short stature: ISS, GHD, mild primary hypothyroidism (high TSH), and isolated TSH-D

\begin{tabular}{|c|c|c|c|c|c|c|c|c|c|}
\hline Group & $n$ & $\begin{array}{l}\text { Female gender } \\
n \text { (\% of group) }\end{array}$ & CA $(y)$ & $\mathrm{BA}(\mathrm{y})$ & $\mathrm{T}_{4}(\mathrm{nmol} / \mathrm{L})$ & $\begin{array}{c}\mathrm{FT}_{4} \\
(\mathrm{pmol} / \mathrm{L}) \\
\end{array}$ & TSH (mU/L) & $\begin{array}{c}\text { Stim GH } \\
(\mu \mathrm{g} / \mathrm{L})\end{array}$ & $\mathrm{mNGH}(\mu \mathrm{g} / \mathrm{L})$ \\
\hline ISS & 151 & $51(34)$ & $11.0 \pm 3.1$ & $9.5 \pm 3.2$ & $102 \pm 19$ & $18 \pm 4$ & $2.5 \pm 1.1$ & $19.4 \pm 4.8$ & $4.1 \pm 2.7$ \\
\hline GHD & 39 & $11(28)$ & $9.1 \pm 4.0$ & $7.0 \pm 3.7 *$ & $103 \pm 23$ & $18 \pm 4$ & $2.8 \pm 1.4$ & $4.8 \pm 1.9^{*}$ & $2.2 \pm 1.8^{*}$ \\
\hline High TSH & 15 & $8(53)$ & $12.0 \pm 4.1$ & $10.8 \pm 3.7$ & $95 \pm 23$ & $15 \pm 3 *$ & $7.3 \pm 2.9 *$ & $17.2 \pm 6.1$ & $3.1 \pm 2.2$ \\
\hline TSH-D & 30 & $4(13)$ & $9.1 \pm 4.5$ & $7.2 \pm 4.1$ & $84 \pm 22 *$ & $15 \pm 3^{*}$ & $2.4 \pm 1.2$ & $18.3 \pm 12.6$ & $4.3 \pm 3.2$ \\
\hline Normal subjects & $96 \dagger$ & & $11.4 \pm 2.0$ & & $\begin{array}{l}100 \pm 30 \\
(64-154)\end{array}$ & $\begin{array}{l}18 \pm 5 \\
(13-26)\end{array}$ & $\begin{array}{l}2.4 \pm 1.5 \\
(1.0-4.8)\end{array}$ & $(7-40) \ddagger$ & $\begin{array}{r}4.0 \pm 3.0 \\
\text { (ref. } 21 \text { ) }\end{array}$ \\
\hline
\end{tabular}

$\mathrm{CA}$, chronologic age; BA, bone age; Stim GH, highest GH concentration after GH stimulation test; mNGH, mean of all GH values during 12-h overnight sampling every $20 \mathrm{~min}$. Values are mean $\pm \mathrm{SD}$.

$* p<0.01$ compared to result in ISS group.

$\dagger$ Data from Rose and Nisula (16).

$\$$ Data from Marin et al. (10). 
Table 3. TSH surge and TRH test results in ISS, GHD, mild primary hypothyroidism (high TSH), and TSH-D

\begin{tabular}{lccccc}
\hline & \multicolumn{2}{c}{ TSH surge } & & \multicolumn{2}{c}{$\begin{array}{c}\text { Magnitude of TSH } \\
\text { Peak after TRH }\end{array}$} \\
\cline { 2 - 3 } \multicolumn{1}{c}{ Group } & $\%$ & $n$ & & TSH (mU/L) & $n$ \\
\hline ISS & $144 \pm 76$ & 151 & & $18.8 \pm 7.5$ & 91 \\
GHD & $106 \pm 68$ & 39 & & $18.9 \pm 7.9$ & 21 \\
High TSH & $124 \pm 47$ & 15 & & $40.3 \pm 8.9^{*}$ & 11 \\
TSH-D & $33 \pm 15^{*}$ & 30 & & $19.3 \pm 10.6$ & 22 \\
Normal subjects & $144 \pm 70$ & 96 & & $16.0 \pm 11$ & 76 \\
& $(50-300) \dagger$ & & & $(9-42) \ddagger$ & \\
\hline
\end{tabular}

Values are mean $\pm \mathrm{SD}$ (95\% confidence limits of normal values).

$* p<0.01$ compared to result in ISS group.

$\dagger$ Data from Rose and Nisula (16).

$\ddagger$ Data from Rose et al. (11).

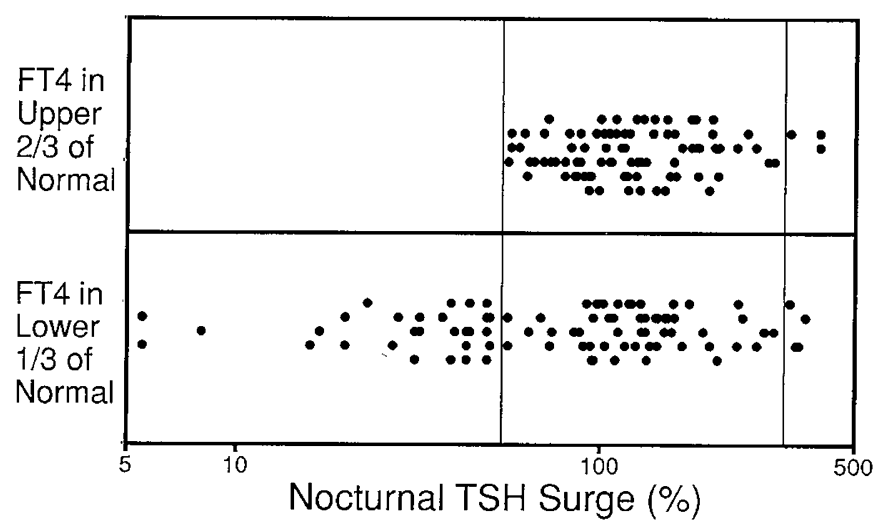

Figure 2. Nocturnal TSH surge in two groups of children with apparent ISS: those with $\mathrm{FT}_{4}$ in the upper two-thirds of the normal range, and those with $\mathrm{FT}_{4}$ in the lowest third of the normal range. Each dot represents the TSH surge result in one child. The two vertical lines at 50\% and 300\% define the upper and lower $95 \%$ confidence limits of normal children reported previously (16).

Levothyroxine treatment during 6 mo resulted in no significant change in growth velocity in either group of ISS children. However, a significant increase in growth velocity was observed in TSH-D during levothyroxine therapy compared with both baseline growth velocity and follow-up growth velocity ( $p=0.03$ and 0.01 , respectively) (Fig. 5). Increase in growth velocity in TSH-D was comparable to that observed in children with primary hypothyroidism when treated. Change in bone age during 6 mo of levothyroxine treatment was not significantly different between groups $(0.7 \pm 0.2$-y change in TSH-D versus $0.6 \pm 0.1 \mathrm{y}$ in ISS, mean $\pm \mathrm{SEM}$ ).

\section{DISCUSSION}

In this study of children referred for evaluation of height shorter than 2 SD below the mean for age, a significant incidence of isolated TSH-D was found (13\%). This was four-fifths of the incidence of classic GHD identified by the author during the same time period. This surprisingly high incidence was a product of using a new diagnostic test, the TSH surge, which has been shown to have increased sensitivity compared with the TRH test in the diagnosis of TSH-D (11). It was possible to use $\mathrm{FT}_{4}$ as a screening test to identify those children most at risk for this disorder. Isolated TSH-D was

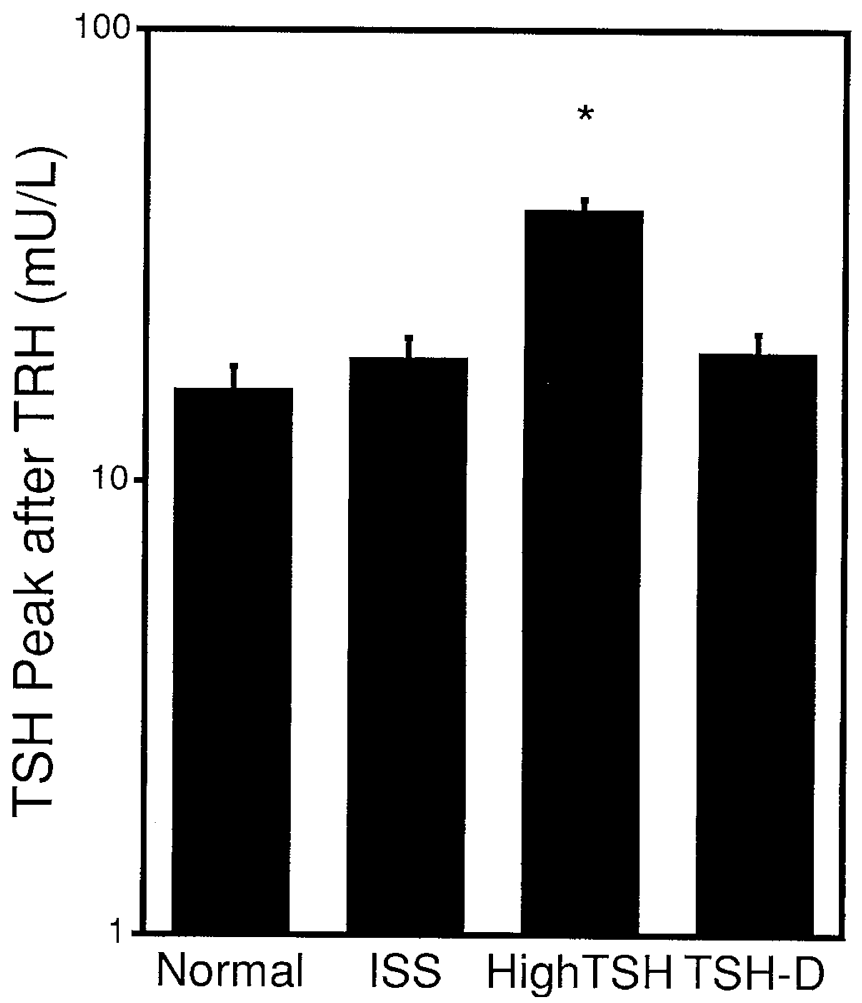

Figure 3. Magnitude of TSH peak response to TRH in normal children (11), ISS children, children with mild primary hypothyroidism (High TSH), and children with isolated TSH-D. Bars show mean \pm SE. The asterisk (*) signifies $p<0.01$ compared with ISS.

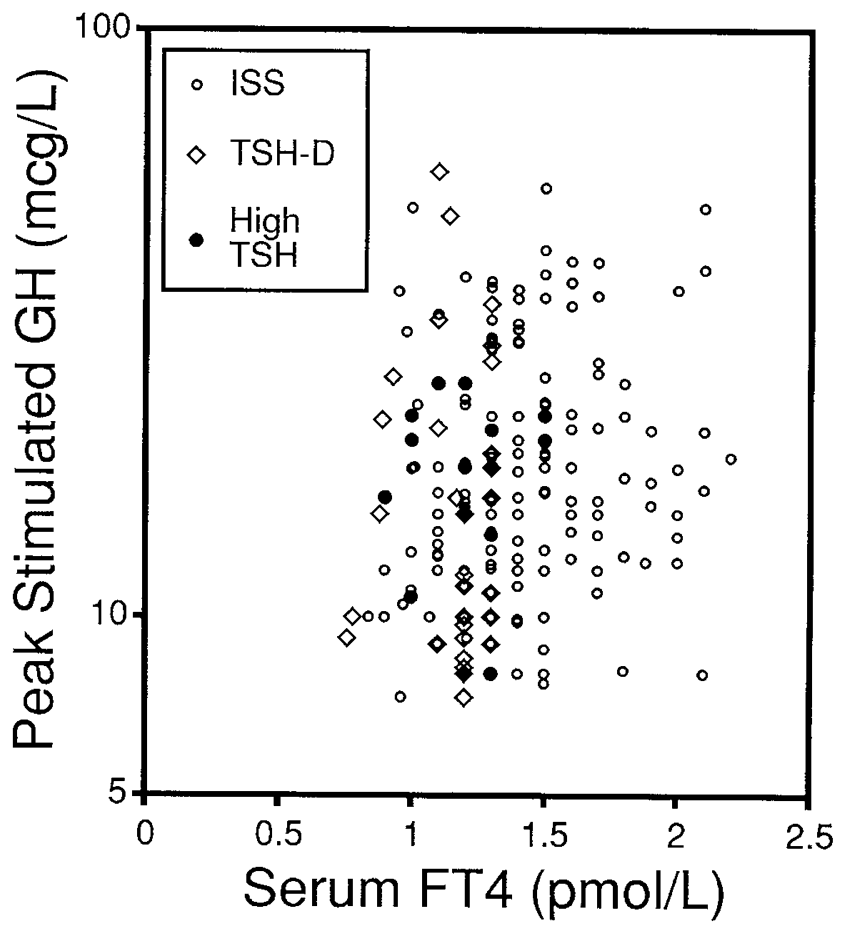

Figure 4. Peak stimulated $\mathrm{GH}$ in relation to $\mathrm{FT}_{4}$ in three groups of children: ISS children, children with mild primary hypothyroidism (High TSH), and children with isolated TSH-D.

identified in $32 \%$ of those short children with $\mathrm{FT}_{4}$ in the lowest third of the normal range.

In contrast, only $9 \%$ of the children with isolated TSH-D would have been identified using a TRH test. This observation 


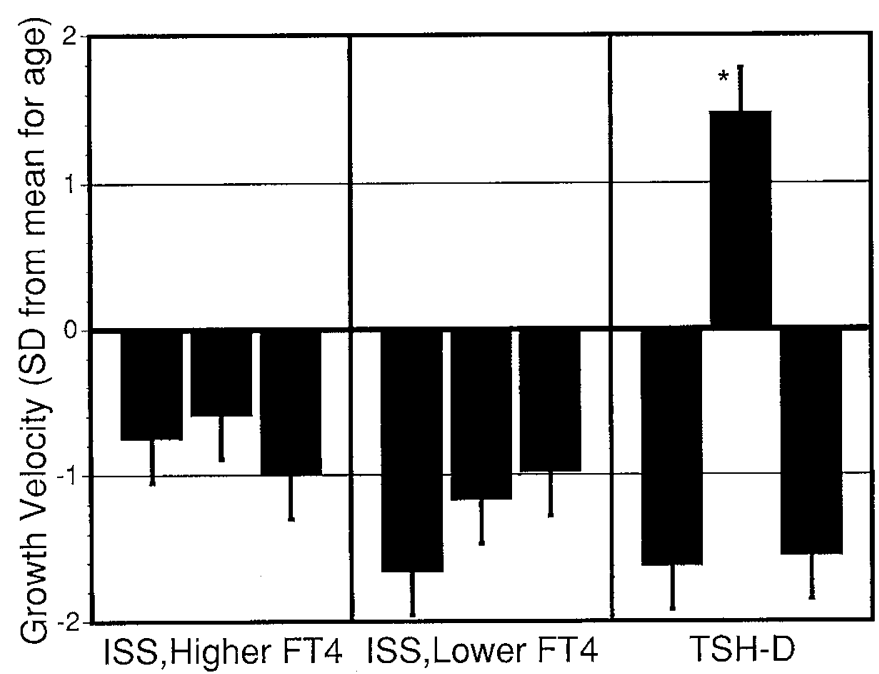

Figure 5. Growth velocity shown in $\mathrm{SD}$ units from the mean for age $(S D)$ at baseline, during a 6-mo period of therapy with levothyroxine, and during a subsequent 6-mo period of follow-up while receiving no therapy, in three groups of children: ISS with $\mathrm{FT}_{4}$ in the upper two-thirds of the normal range (ISS, Higher $F T_{4}$ ), ISS with $\mathrm{FT}_{4}$ in the lowest third of the normal range (ISS, Lower $F T_{4}$ ), and isolated TSH-D. Bars show mean \pm SE. The asterisk (*) signifies $p<0.05$ compared with baseline growth velocity.

is consistent with the finding by the author and others that, although i.v. TRH has been the most frequent test used to confirm TSH-D, 50-85\% of patients with TSH-D have demonstrated a TSH response to TRH which was normal in both amplitude and timing $(11,13,22)$. Thus, there is a significant overlap between the normal pattern of TSH response to TRH and that seen in hypothalamic disorders of TSH release. In a patient with TSH-D, the TSH response to TRH may be abnormal and confirm the disorder or may resemble the response to TRH seen in primary hypothyroidism, but is even more likely to be normal and miss the diagnosis $(11,13,22,54)$.

Children with TSH-D given levothyroxine therapy for 6 mo had a significant increase in growth velocity, whereas ISS children given similar doses for 6 mo did not significantly increase their growth velocity. Growth velocity in hypothyroidism has been described to be sensitive to small changes in thyroid hormone concentration in the absence of other symptoms of hypothyroidism (23). The results of the pilot treatment study suggest that short children with blunted TSH surge and slow growth velocity will probably benefit from thyroid hormone therapy.

The mild degree of hypothyroidism observed in these children with either TSH-D or mild primary hypothyroidism did not result in "low" GH responses to stimulation tests or in low overnight $\mathrm{GH}$ measures. This suggests that $\mathrm{GH}$ evaluation can be accurately performed simultaneously with TSH evaluation in children with $\mathrm{FT}_{4}$ in the lower third of the normal range.

At a practical level it is difficult to cause a false positive blunting of the TSH surge. Artifactual blunting of the TSH surge can occur after fasting (24) (Rose SR, unpublished observation); however, this was not the cause in the current study where the testing conditions included a standard ageappropriate diet with monitored intake. Delayed time of falling asleep or altered quality of sleep in the hospital will not cause a blunted TSH surge. In fact, poor sleep or delayed sleep latency result in augmentation of the rise in $\mathrm{TSH}$ at night (25). For these reasons, blunting of the TSH surge is rare in the test setting and commonly correlates with true clinical abnormality rather than artifact.

Transient or permanent alteration of the TSH surge has been described in hypercortisolemia (26), critical illness (27-30), postoperative recovery (31), hyperglycemia (32), chronic renal failure $(33,34)$, depression (35-38), and aging (39). None of these was present in the children studied in this project. Mild primary hypothyroidism does not significantly alter the TSH surge $(11,40)$.

TSH-D can be observed in association with any etiology of hypothalamic-pituitary disorder $(11,13,17,41)$. It is present as a second deficiency in approximately $10-25 \%$ of children with idiopathic GHD and in 25-50\% of children with organic causes of hypopituitarism (11-14). However, isolated TSH-D is thought to be rare and reportable. The case reports in the literature tend to be of patients with low serum TSH and no response to TRH. Congenital hypothyroidism with low TSH concentrations due to abnormality of the $\beta$ subunit of the TSH molecule has been described in several Japanese and Greek families (42-45). A dozen other individuals with isolated TSH deficiency (low TSH levels and failure to respond to TRH) have been reported (46-51). There are only two case reports of isolated TRH deficiency, one after meningitis, and one proposed to be secondary to hypophysitis $(52,53)$. In contrast, the abnormalities in circadian pattern of TSH concentrations reported in the current study are less easily recognized without specialized testing such as the TSH surge. However, testing of the TSH surge has only recently been used in diagnosis. It is probable that, to date, testing methods have been inadequately sensitive to identify this condition without the presence of strong clinical suspicion.

The mechanism by which isolated TSH-D occurs could include limitation of hypothalamic TRH secretion, alteration of neuroendocrine signals mediating the circadian clock, or alteration of the structure of the TSH molecule $(13,14,51)$. The abnormality could be congenital or could result from subtle birth injury, infection, mild head injury, or other acquired cause.

Subtle or subclinical primary hypothyroidism ("lownormal" thyroid function tests with an elevated TSH) is a commonly recognized clinical condition. In the setting of TSH-D (low-normal thyroid function tests with TSH in the normal range), the diagnosis is usually not made because the patient is unable to elevate TSH concentrations. Thus, TSH-D is a subtle abnormality which is often missed in clinical and laboratory diagnosis of the etiology of short stature. Loss of the nocturnal serum TSH rise represents impairment of TSH secretion which is not revealed by baseline morning measures of TSH or evaluation of the TSH response to TRH. The absence of rise in TSH secretion at night (approximately 30\% of the total daily TSH secretion) is associated with a proportionate decrease both in stimulation of the thyroid gland and in total iodothyronine production. This decrease, although subtle, may be enough to account for slowed growth in some children otherwise thought to have ISS. Subtle hypothyroidism can also 
result in delay of maturation, perhaps contributing in an occasional child to a clinical picture similar to that seen in constitutional delay of puberty.

In short children where the cause of slow growth may otherwise be obscure, $\mathrm{FT}_{4}$ can be used to screen for those short children most likely to have this abnormality. The fact that $\mathrm{FT}_{4}$ can be used as a screening test for those at risk permits important cost-efficacy. TSH surge testing is indicated only in those short children (2 or more SD below the mean for age) whose growth velocity is slow and whose $\mathrm{FT}_{4}$ value is in the lowest third of the normal range. Thus, use of this test can be targeted or reserved using $\mathrm{FT}_{4}$ as a screening test.

In children with short stature ( $-2 \mathrm{SD})$, slow growth velocity with or without evidence of pubertal delay, and a $\mathrm{FT}_{4}$ in the lower third of normal, the next diagnostic step should be a TSH surge study with GH stimulation tests. Such children have a one in three chance of subtle TSH-D. This is a significant incidence of a diagnosable and treatable cause of short stature.

Acknowledgments. The author thanks Bruce Nisula for his mentoring support and persistent questions, Giovanna Municchi for her steadfast reliability, and Penelope Manasco for her enthusiasm in scientific inquiry. The study could not have been performed without the consistent efforts of the nurses in the 9 West nursing unit of the National Institutes of Health, and in the Clinical Research Centers of the University of New Mexico and the University of Tennessee, Memphis. Finally, I appreciate the support of my current colleagues: Stephen Burstein, George Burghen, Vicki Hodnicak, Sheila Shope, Robert Lustig, Vicki Robley, and Pisit Pitukcheewanont.

\section{REFERENCES}

1. Schaff-Blass E, Burstein S, Rosenfield RL 1984 Advances in diagnosis and treatment of short stature, with special reference to the role of growth hormone. J Pediatr 104:801-813

2. Burstein S 1986 Short stature. In: Gellis SS, Kagan BM (eds) Current Pediatric Therapy, 12th Ed. WB Saunders, Philadelphia, pp 296-299

3. Mahoney CP 1987 Evaluating the child with short stature. Pediatr Clin North Am $34: 825-849$

4. Rose SR 1995 Are we overtreating adolescents with growth hormone? Endocrinologist 5:113-117

5. Spiliotis BE, August GP, Hung W, Sonis W, Mendelson W, Bercu BB 1984 Growth hormone neurosecretory dysfunction: a treatable cause of short stature. JAMA 251:2223-2230

6. Zadik Z, Chalew SA, Raiti S, Kowarski AA 1985 Do short children secrete insufficient growth hormone? Pediatrics 76:355-360

7. Bercu BB, Shulman D, Root AW, Spiliotis BE 1986 Growth hormone (GH) provoc ative testing frequently does not reflect endogenous GH secretion. J Clin Endocrinol Metab 63:709-716

8. Rose SR, Ross JL, Uriarte M, Barnes KM, Cassorla FG, Cutler Jr GB 1988 The advantage of measuring stimulated as compared with spontaneous growth hormone levels in the diagnosis of growth hormone deficiency. N Engl $J$ Med 319:201-207

9. Rose SR 1991 Overnight studies of growth hormone for the diagnosis of growth hormone deficiency. Endocrinologist 1:25-32

10. Marin G, Domené HM. Barnes KM, Blackwell BJ, Cassorla FG, Cutler GB Jr 1994 The effects of estrogen priming and standardized response to hormone provocative tests in normal children and adolescents: treadmill exercise and arginine-insulin in normal boys and girls. J Clin Endocrinol Metab 79:537-541

11. Rose SR, Manasco PK, Pearce S, Nisula BC 1990 Hypothyroidism and deficiency of the nocturnal thyrotropin surge in children with hypothalamic-pituitary disorders. J Clin Endocrinol Metab 70:1750-1755

12. Municchi G, Malozowski S, Nisula BC, Cristiano A, Rose SR 1992 Nocturnal TSH surge in growth hormone deficient children. J Pediatr 121:214-220

13. Samuels MH, Ridgway EC 1992 Central hypothyroidism. Endocrinol Metab Clin North Am 21:903-919

14. Manasco PK, Blithe DL, Rose SR, Gelato MC, Magner JA, Nisula BC 1994 Thyrotropin abnormalities in central hypothyroidism. In: Lustbader JW (ed) Glycoprotein Hormones: Structure, Function and Clinical Implications. Serono Symposia, Springer-Verlag, New York, pp 343-348
15. Mantagos S, Koulouris A, Makri M, Vagenakis AG 1992 Development of thyrotropin circadian rhythm in infancy. J Clin Endocrinol Metab 74:71-74

16. Rose SR, Nisula BC 1989 Circadian variation of thyrotropin in childhood. J Clin Endocrinol Metab 68:1086-1090

17. Caron PJ, Nieman LK, Rose SR, Nisula BC 1986 Deficient nocturnal surge of thyrotropin in central hypothyroidism. J Clin Endocrinol Metab 62:960-964

18. Azukizawa M, Perkary AE, Hershman JM, Parker DC 1976 Plasma thyrotropin, thyroxine, and triiodothyronine relationships in man. J Clin Endocrinol Metab 43:533-542

19. Custro N, Scaglione R 1980 Circadian rhythm of TSH in adult men and women. Acta Endocrinol 95:465-471

20. Brabant G, Frank K, Hoang-Vu C, Hesch RD, Von zur Mühlen A 1991 Hypothalamic regulation of pulsatile thyrotropin secretion. $J$ Clin Endocrinol Metab 72:145-150

21. Rose SR, Municchi G, Barnes KM, Kamp GA, Uriarte MM, Ross JL, Cassorla F, Cutler GB Jr 1991 Spontaneous growth hormone secretion increases during puberty in normal girls and boys. J Clin Endocrinol Metab 73:428-435

22. Patel YC, Burger HG 1973 Serum thyrotropin (TSH) in pituitary and/or hypothalamic hypothyroidism: normal or elevated basal levels and paradoxical responses to thyrotropin-releasing hormone. J Clin Endocrinol Metab 37:190-196

23. Ren SG, Huang Z, Sweet DE, Malozowski S, Cassorla F 1990 Biphasic response of rat tibial growth to thyroxine administration. Acta Endocrinol 122:3-5

24. Romijn JA, Adriaanse R, Brabant G, Prank K, Endert E, Wiersinga WM 1990 Pulsatile secretion of thyrotropin during fasting: a decrease of thyrotropin pulse amplitude. J Clin Endocrinol Metab 70:1631-1636

25. Kasper S, Sack DA, Wehr TA, Kick H, Voll G, Vieira A 1988 Nocturnal TSH and prolactin secretion during sleep deprivation and prediction of antidepressant response in patients with major depression. Biol Psychiatry 24:631-641

26. Bartalena L, Martino E, Petrini L, Velluzzi F, Loviselli A, Grasso L, Mammoli C, Pinchera A 1991 The nocturnal serum thyrotropin surge is abolished in patients with adrenocorticotropin (ACTH)-dependent or ACTH-independent Cushing's syndrome. J Clin Endocrinol Metab 72:1195-1199

27. Custro N, Scafidi V, Notarbartolo A 1992 Alterations in circadian rhythm of serum thyrotropin in critically ill patients. Acta Endocrinol 127:18-22

28. Custro N, Scafidi V, Gallo S, Notarbartolo A. 1994 Deficient pulsatile thyrotropin secretion in the low-thyroid-hormone state of severe non-thyroidal illness. Eur $\mathrm{J}$ Endocrinol 130:132-136

29. Arem R, Deppe S 1990 Fatal nonthyroidal illness may impair nocturnal thyrotropin levels. Am J Med 88:258-262

30. Romijn JA, Wiersinga WM 1990 Decreased nocturnal surge of thyrotropin in nonthyroidal illness. J Clin Endocrinol Metab 70:35-42

31. Bartalena L, Martino E, Brandi LS, Falcone M, Pacchiarotti A, Ricci C, Bogazzi F, Grasso L, Mammoli C, Pinchera A 1990 Lack of nocturnal serum thyrotropin surge after surgery. J Clin Endocrinol Metab 70:293-296

32. Bartalena L, Cossu E, Grasso L, Velluzzi F, Loviselli A, Cirillo R, Martino E 1993 Relationship between nocturnal serum thyrotropin peak and metabolic control in diabetic patients. J Clin Endocrinol Metab 76:983-987

33. Bartalena L, Pacchiarotti A, Palla R, Antonangeli L, Mammoli C, Monzani $F$, DeNegri F, Panichi V, Martino E, Baschieri L, Pinchera A 1990 Lack of nocturnal serum thyrotropin (TSH) surge in patients with chronic renal failure undergoing regular maintenance hemofiltration: a case of central hypothyroidism. Clin Nephrol $34: 30-34$

34. Pasqualini T, Zantleifer D, Balzaretti M, Granillo E, Fainstein-Day P, Ramirez J, Ruiz S, Gutman R, Ferraris J 1991 Evidence of hypothalamic-pituitary thyroid abnormalities in children with end-stage renal disease. J Pediatr 118:873-878

35. Bartalena L, Placidi GF, Martino E, Falcone M, Pellegrini L, Dell'Osso L, Pacchiarotti A, Pinchera A 1990 Nocturnal serum thyrotropin (TSH) surge and the TSH response to TSH-releasing hormone: dissociated behavior in untreated depressives. $\mathbf{J}$ Clin Endocrinol Metab 71:650-655

36. Duval F, Mokrani MC, Oliveira Castro J, Crocq MA, Andrade EE, Macher JP 1992 Circadian effects on the TSH response to TRH in depressed patients. Clin Neuropharmacol 15:384A-385A

37. Coiro V, Volpi R, Marchesi C, De Ferri A, d'Amato L, Caffarri G, Davollo M, Rossi E, Caffarra P, Chiodera P 1994 Lack of seasonal variation in abnormal TSH secretion in patients with seasonal affective disorder. Biol Psychiatry 35:36-41

38. Sakaue K 1990 Studies on the factors affecting serum thyrotropin levels in healthy controls and on the thyroid function in depressed patients using a highly sensitive immunoassay. Folia Endocrinol Jpn 66:1094-1107

39. Murialdo G, Costelli P, Fonzi S, Parodi C, Torre F, Cenacchi T, Polleri A 1993 Circadian secretion of melatonin and thyrotropin in hospitalized aged patients. Aging $5: 39-46$

40. Adriaanse R, Brabant G, Prank K, Endert E, Wiersinga WM 1992 Circadian changes in pulsatile TSH release in primary hypothyroidism. Clin Endocrinol 37:504-510

41. Adriaanse R, Brabant G, Endert E, Wiersinga WM 1993 Pulsatile thyrotropin release in patients with untreated pituitary disease. J Clin Endocrinol Metab 77:205-209

42. Hayashizaki Y, Hiraoka Y, Endo Y, Miyai K, Matsubara K 1989 Thyroid-stimulating hormone (TSH) deficiency caused by a single base substitution in the CAGYC region of the $\beta$-subunit. EMBO J 8:2291-2296

43. Hayashizaki Y, Hiraoka Y, Tatsumi K, Hashimoto T, Furuyama J, Miyai K, Nishijo K, Matsuura M, Kohno H, Labbe A, Matsubara K. 1990 Deoxyribonucleic acid analyses of five families with familial inherited thyroid stimulating hormone deficiency. J Clin Endocrinol Metab 71:792-796

44. Mori R, Sawai T, Kinoshita E, Baba T, Matsumoto T, Yoshimoto M, Tsuji Y, Satake Y, Sawada K 1991 Rapid detection of a point mutation in thyroid-stimulating hormone $\beta$-subunit gene causing congenital isolated thyroid-stimulating hormone deficiency. Jpn J Hum Genet 36:313-316 
45. Dacou-Voutetakis C, Feltquate DM, Drakopoulou M, Kourides IA, Dracopoli NC 1990 Familial hypothyroidism caused by a nonsense mutation in the thyroidstimulating hormone $\beta$-subunit gene. Am J Hum Genet 46:988-993

46. Sachson R, Rosen SW, Cuatrecases P, Roth J, Frantz AG 1972 Prolactin stimulation by thyrotropin-releasing hormone in a patient with isolated thyrotropin deficiency. $\mathrm{N}$ Engl J Med 287:972-973

47. Labbe A, Dubray C, Gaillard G, Besse G, Assali P, Malpuech G 1984 Familial growth retardation with isolated thyroid-stimulating hormone deficiency. Clin Pediatr 23:675-678

48. Kadrnka-Lovrencic M, Knezevic J, Ligutic I, Oberiter V 1984 A boy with congenital hypothalamic hypothyroidism. Acta Med Iugoss 38:215-222

49. Foresti V, Parisio E 1985 [Secondary hypothyroidism with thyrotropic hormone deficiency. Presentation of a case and review of the literature). Minerva Med $76: 2323-2327$
50. Rosenberg T, Ramot Y, Gilboa Y 1985 [Central hypothyroidism due to isolated thyroid stimulating and thyrotropin releasing hormone deficiencies]. Harefuah 108:429-431

51. Vannelli S, Conrieri M, Tosi C, Fedele A, Giordanino S, Elena MG, Murru PC 1992 Description of a case of empty sella with isolated TSH deficiency. Minerva Pediat 44:43-45

52. Chandra M, Lifshitz F, Fort P, deRosas FJ, Kantrow A 1977 Isolated thyrotropin deficiency in diabetes mellitus. Acta Endocrinol 84:80-86

53. Katakami H, Kato Y, Inada M, Imura H 1984 Hypothalamic hypothyroidism due to isolated thyrotropin-releasing hormone (TRH) deficiency. I Endocrinol Invest 7:231-233

54. Faglia G, Bitensky L, Pinchera A, Ferrari C, Paracchi A, Beck-Peccoz P, Ambrosi B, Spada A 1979 Thyrotropin secretion in patients with central hypothyroidism: evidence for reduced biological activity of immunoreactive thyrotropin. J Clin Endocrinol Metab 48:989-998 